\title{
The African State and Environmental Management: A Review of Climate and Human Security
}

\author{
Emmanuel M. Ome, Ani Casimir \\ Department of Philosophy, University of Nigeria, Nsukka, Nigeria \\ Email: dromemma@yahoo.com, cepperngo@yahoo.com
}

Received 26 February 2015; accepted 16 March 2015; published 18 March 2015

Copyright (C) 2015 by authors and Scientific Research Publishing Inc.

This work is licensed under the Creative Commons Attribution International License (CC BY). http://creativecommons.org/licenses/by/4.0/

(c) (i)

\begin{abstract}
Climate Change is a pressing human security issue. It can create and increase risk and vulnerability for many people in many regions, most especially those people for whom themselves and their state and sub-state systems leave them least able to respond. This paper examines the existing and potential impacts of climate change on human Security, and finally provides the way forward to addressing the challenges of climate change on human security.
\end{abstract}

\section{Keywords}

Climate Change, Mitigation, Adaptation, Environmental Management, Human Security, The Africa State

\section{Introduction}

Climate change has been identified as one of the greatest threats to humanity of all times, a threat to human security in addition to producing adverse environmental conditions such as rising sea level, drought, crop failure, vector-borne diseases, extreme events, degradation of water/air quality, heat waves, etc. In turn, threats to human security threaten human rights. Climate change is already challenging the realization of a broad range of internationally protected human rights, such as rights to food, water, environment, health, shelter, property, and education; rights associated with livelihood and culture; with migration and resettlement; with democratization and self-determination; political and social stability; and with personal security in the event of crime and conflict. This paper examines the existing and potential impacts of climate change on human Security, and finally provides the way forward to addressing the challenges of climate change on human security. 


\subsection{Conceptual Framework}

\subsubsection{Climate Change}

Climate Change is any systematic change in the long-term statistics of climate elements (such as temperature, pressure, or winds) sustained over several decades or longer. Climate change may be due to natural external forcing, such as changes in solar emission or slow changes in the earth's orbital elements; natural internal processes of the climate system; or anthropogenic forcing. Climate Change is associated with a myriad of socioeconomic and biophysical shifts, but potential and projected changes in climate variability, including increases in extreme event frequency or intensity, is well recognized as a central societal concern.

This has led to a growing body of research on the aggregate estimates of the economic and social costs of climate change in terms of human mortality and morbidity, gross domestic product (GDP), infrastructure, and capital resources that may be affected by extreme events. There is also a growing recognition of the need to prepare for and manage the effects of extreme weather events under climate change. Although technical responses related to hazards and climate impacts have long been considered important, over the past decades attention has shifted to a focus on vulnerability and particularly on the role that climate change adaptation and disaster risk reduction can play in reducing vulnerability to climate variability, hazards and extreme events.

\subsubsection{Human Security}

Human security refers to an emerging paradigm for understanding global vulnerabilities whose proponents challenge the traditional notion of national security by arguing that the proper referent for security should be the individual rather than the state. Human security holds that a people-centred view of security is necessary for national, regional and global stability. The UNDP Human Development Report (1994) defined human security as:

Safety from chronic threats such as hunger, disease, and repression as well as protection from sudden and harmful disruptions in the patterns of daily life-whether in homes, in jobs or in communities, and as the totality of economic security, food security, health security, environmental security, personal security, community security and political security.

Human security has become "both a new measure of global security and a new agenda for global action." Culture, economies, trade, production-lines, values, politics are no longer framed within national boundaries, peoples of the world are connected through their actions and inactions, and as such threats to security and livelihoods transcend state apparatus. Human security necessitates a more global approach than traditional national security to respond to threats that hold no respect for national borders. Security literature is no longer simply concerned with wars between states, but also with a human-centric approach to security and to addressing effects of internal conflicts on the civilian population; the effects of social, physical and environmental degradation on all individuals; and the impacts of terrorism and organised crime (Folke, 2006: p. 45).

Human security in its broadest sense embraces far more than the absence of violent conflict. It encompasses human rights, good governance, access to education and health care, and ensuring that each individual has opportunities and choices to fulfil his or her potential... Freedom from want, freedom from fear and the freedom of the future generations to inherit a healthy natural environment-these are the interrelated building blocks of human, and therefore national security.

\section{Climate Change-A Profile of Causes}

Climate changes are caused by a rash of causes-Natural and Man-Made. Natural causes are worsened by manmade factors. There are a number of natural factors responsible for climate change. Some of the more prominent ones are continental drift, volcanoes, ocean currents, the earth's tilt, and comets and meteorites. Let's look at them in a little detail. The earth's climate is dynamic and always changing through a natural cycle. What the world is more worried about is that the changes that are occurring today have been speeded up because of man's activities. These changes are being studied by scientists all over the world who are finding evidence from tree rings, pollen samples, ice cores, and sea sediments. The causes of climate change can be divided into two categories - those that are due to natural causes and those that are created by man.

\subsection{Continental Drift}

The continents were all part of one large landmass. Proof of this comes from the similarity between plant and 
animal fossils and broad belts of rocks found on the eastern coastline of South America and western coastline of Africa, which are now widely separated by the Atlantic Ocean. The discovery of fossils of tropical plants (in the form of coal deposits) in Antarctica has led to the conclusion that this frozen land at some time in the past, must have been situated closer to the equator, where the climate was tropical, with swamps and plenty of lush vegetation.

The continents that we are familiar with today were formed when the landmass began gradually drifting apart, millions of years back. This drift also had an impact on the climate because it changed the physical features of the landmass, their position and the position of water bodies. The separation of the landmasses changed the flow of ocean currents and winds, which affected the climate. This drift of the continents continues even today; the Himalayan range is rising by about $1 \mathrm{~mm}$ (millimeter) every year because the Indian land mass is moving towards the Asian land mass, slowly but steadily.

\subsubsection{Volcanoes}

When a volcano erupts it throws out large volumes of sulphur dioxide $\left(\mathrm{SO}_{2}\right)$, water vapour, dust, and ash into the atmosphere. Although the volcanic activity may last only a few days, yet the large volumes of gases and ash can influence climatic patterns for years. Millions of tonnes of sulphur dioxide gas can reach the upper levels of the atmosphere (called the stratosphere) from a major eruption. The gases and dust particles partially block the incoming rays of the sun, leading to cooling. Sulphur dioxide combines with water to form tiny droplets of sulphuric acid. These droplets are so small that many of them can stay aloft for several years. They are efficient reflectors of sunlight, and screen the ground from some of the energy that it would ordinarily receive from the sun. Winds in the upper levels of the atmosphere, called the stratosphere, carry the aerosols rapidly around the globe in either an easterly or westerly direction. Movement of aerosols north and south is always much slower.

Volcanic eruptions of this magnitude can reduce the amount of solar radiation reaching the Earth's surface, lowering temperatures in the lower levels of the atmosphere (called the troposphere), and changing atmospheric circulation patterns. The extent to which this occurs is an ongoing debate.

\subsubsection{The Earth's Tilt}

The earth makes one full orbit around the sun each year. It is tilted at an angle of $23.5^{\circ}$ to the perpendicular plane of its orbital path. For one half of the year when it is summer, the northern hemisphere tilts towards the sun. In the other half when it is winter, the earth is tilted away from the sun. If there was no tilt we would not have experienced seasons. Changes in the tilt of the earth can affect the severity of the seasons-more tilt means warmer summers and colder winters; less tilt means cooler summers and milder winters.

The Earth's orbit is somewhat elliptical, which means that the distance between the earth and the Sun varies over the course of a year. We usually think of the earth's axis as being fixed, after all, it always seems to point toward Polaris (also known as the Pole Star and the North Star). Actually, it is not quite constant: the axis does move, at the rate of a little more than a half-degree each century. So Polaris has not always been, and will not always be, the star pointing to the North. When the pyramids were built, around $2500 \mathrm{BC}$, the pole was near the star Thuban (Alpha Draconis). This gradual change in the direction of the earth's axis, called precession is responsible for changes in the climate.

\subsection{Human Causes}

The Industrial Revolution in the 19th century saw the large-scale use of fossil fuels for industrial activities. These industries created jobs and over the years, people moved from rural areas to the cities. This trend is continuing even today. More and more land that was covered with vegetation has been cleared to make way for houses. Natural resources are being used extensively for construction, industries, transport, and consumption. Consumerism (our increasing want for material things) has increased by leaps and bounds, creating mountains of waste. Also, our population has increased to an incredible extent.

Cars, buses, and trucks are the principal ways by which goods and people are transported in most of our cities. These are run mainly on petrol or diesel, both fossil fuels. We generate large quantities of waste in the form of plastics that remain in the environment for many years and cause damage. We use a huge quantity of paper in our work at schools and in offices. Have we ever thought about the number of trees that we use in a day? Timber is used in large quantities for construction of houses, which means that large areas of forest have to be cut down. 
A growing population has meant more and more mouths to feed. Because the land area available for agriculture is limited (and in fact, is actually shrinking as a result of ecological degradation!), high-yielding varieties of crop are being grown to increase the agricultural output from a given area of land. However, such high-yielding varieties of crops require large quantities of fertilizers; and more fertilizer means more emissions of nitrous oxide, both from the field into which it is put and the fertilizer industry that makes it. Pollution also results from the run-off of fertilizer into water bodies.

\section{Effects of Climate Change}

Many climate change experts going for Climate conferences are being trapped the world over by erratic weather patterns. Incidences of meningitis have been on the increase especially in Nigeria for the past one-year as a result of excessive heat. In Nigeria the eleven frontline states in the north that have suffered from desert encroachment have been suffering from heat related ailments.

It is generally known that the disease attacks more people during the dry season because of dust, wind and cold nights. There were indications in the recent times that many people were treated for acute pneumonia in some hospitals as a result of the erratic and unpredictable weather which has also confused farmers about planting seasons raising fear about food production and security.

Apart from the reign of diseases as a result of harsh weather conditions in Northern Nigeria, agriculture has been affected as a result of erratic weather patterns. The dryness has led to dry waterbeds and movement of people and their pasture to the southern regions thus causing tension and conflicts between the original inhabitants and the new comers.

In one of his treatise on Climate Change in Nigeria and Niger, Professor Emmanuel Oladipo, a United Nations Development Programme (UNDP) Consultant and Nigeria/Niger Project, Niamey, confirmed that Climate change is a serious threat to efforts at poverty eradication, and sustainable development in Nigeria and Niger because the countries have large rural population directly depending on climate sensitive economic and development sectors (agriculture and fisheries).

In the southern states, Tuberculosis has been on the increase. Dr. Nath Ayo Macualay Medical Director, Macaulay Medical centre, Mushin, Lagos told The Guardian that apart from heat rashes that had been noticed amongst the populace within the period of intense heat, there has been an upsurge in Tuberculosis (TB) in recent times. The writer insists that geo-engineering solutions must be in addition to, not replace, dramatic emission reductions if society is to avoid the most dangerous impacts from climate change.

\section{Human Security Implications of Climate Change}

There is growing recognition among scientists, practitioners, and policy-makers that climate change will increase the frequency and magnitude of extreme hydro-meteorological events with potentially devastating economic and social impacts at the local and regional levels. Disasters are increasing in impacts and scope, not due to hazards alone, but because of the combined effects of large-scale environmental, economic, social, demographic, and technological changes (Reuveny, 2007: p. 232). Climate change and the potential for increased disasters related to extreme events also raise critical concerns for long-term human security. Human security, broadly defined, includes the means to secure basic rights, needs, and livelihoods, and to pursue opportunities for human fulfilment and development. The promotion of human security is also closely linked to a "positive vision" of society that is encapsulated in notions such as well-being, quality of life, and human flourishing. This positive vision has been elaborated through the capabilities approach, which emphasizes the freedom of people to choose among different ways of living, and to pursue opportunities to achieve outcomes that they value.

A number of recent studies (Bohle, Downing, \& Watts, 1995) have assessed the relationship between climate change and human security, demonstrating that the linkages are often both complex and context-dependent. For example, negative impacts of climate change on food security over the medium- and long-term are likely to create greater emergency food aid needs in the future. Among the most widely-discussed humanitarian and human security issues surrounding climate change are the possibilities of mass migration and/or violent conflict as the result of biophysical or ecological disruptions associated with climate change.

\section{Climate Change and Underdevelopment: An African Perspective}

The general debate in Africa unmistakeably points to the fact that climate change will affect the continent nega- 
tively. Despite the acceptance of this phenomenon and its negative implications, the debate about its policy implications and socio-economic impact on the people of Africa continue. Climate change will affect Africa profoundly and the fear is that but the continent lacks the resources of the developed world to cope with its feared negative fallouts and effects (Albala-Bertrand, 2000). Through research, public education and policy analysis, the African state and the civil society hope to contribute a successful collective and collaborative response to manage this debilitating challenge represented by the destructive, adaption, mitigation and under-developmental potentials of this historical environmental challenge to Africa. This explains why Franklyn Lisk (2005: p. 378) poses the following questions and draws the sense of urgency and risk for Africa in his work entitled "The Current Climate Change Situation in Africa”:

Africa has much at stake. The key question is: how can Africa make a Copenhagen deal relevant to the impact of climate change on its economies and populations? To address this question, we need to explore the link between climate change and socioeconomic conditions that intensify underdevelopment and poverty in Africa, and examine the different pathways through which climate change affects Africa's development (Berkhout, 2005). We also need to highlight the opportunity that Copenhagen can create for Africa to adapt to new, more efficient patterns of development that reduce its vulnerability and improve its resilience.

\section{Recommendations on Better Management and Security}

Climate change already poses an immediate and far-reaching threat to people and communities around the world and has implications for the full enjoyment of human rights, as recognised by the UN Human Rights Council's Human Rights and Climate Change Resolution adopted by consensus earlier this year. The international community's response to climate change must include redress of those rights violated by climate change both because of international human rights obligations, and also because of the role as polluters in creating anthropogenic climate change and its resultant impacts on vulnerable communities (O’Brien \& Leichenko, 2006: p. 156).

The human security discourse clearly shows the global nature of climate change and the myriad local problems it will cause particularly for those least able to respond, suggesting the need for an international response. The human rights discourse adds the dimension of a responsibility of redress by polluters to the victims of their polluting; of a moral and legal imperative to respond to the insecurity brought on others who are not responsible for causing anthropogenic climate change. The right to life and security, to subsistence, to health, and to food will all be impacted upon by climate change among vulnerable populations (Scheffran, 2008: p. 15). The international response to climate change must therefore be two-fold:

- to significantly reduce global emissions to prevent further climate change by committing to keeping global warming below $2^{\circ} \mathrm{C}$, and

- to protect the rights and security of those people who will be affected by the now-unavoidable impacts by enabling them to adapt.

\section{Conclusion}

Adaptation to climate change will be an enormous challenge for society over the next several decades. Key points emphasized throughout this paper are that disaster risk reduction and climate change adaptation are of critical importance to the security of millions of people (Lie, 2007: p. 21), and that vulnerability reduction can serve as a cornerstone for strategies to reduce the negative outcomes of climate change. In considering the linkages between disaster risk reduction, climate change adaptation and human security (Brown, Hammill, \& McLeman, 2007), it is important to recognize that human security is not simply about freedom from conflict or prevention of population displacement. Human security is closely linked to the development of human capabilities in the face of change and uncertainty. Individuals and communities faced with both rapid change and increasing uncertainty are challenged to respond in new ways that protect their social, environmental, and human rights.

\section{References}

Albala-Bertrand, J. M. (2000). Responses to Complex Humanitarian Emergencies and Natural Disasters: An Analytical Comparison. Third World Quarterly, 21, 215. http://dx.doi.org/10.1080/01436590050004328

Berkhout, F. (2005). Rationales for Adaptation in EU Climate Change Policies. Climate Change, 5, 377. 
Bohle, H., Downing, T., \& Watts, M. (1995). Climate Change and Social Vulnerability: Toward a Sociology and Geography of Food Insecurity. Global Environmental Change, 4, 37. http://dx.doi.org/10.1016/0959-3780(94)90020-5

Brown, O., Hammill, A., \& McLeman, R. (2007). Climate Change: The New Security Threat. International Affairs, 83, 1141. http://dx.doi.org/10.1111/j.1468-2346.2007.00678.x

Folke, C. (2006). Resilience: The Emergence of a Perspective for Social-Ecological Systems Analyses. Global Environmental Change, 16, 253. http://dx.doi.org/10.1016/j.gloenvcha.2006.04.002

Lie, J. (2007). Global Climate Change and the Politics of Disaster. Sustainable Science, 2, 233. http://dx.doi.org/10.1007/s11625-007-0026-9

O’Brien, K. L., \& Leichenko, R. M. (2006). Climate Change, Equity and Human Security. Die Erde, 137, 165.

Reuveny, R. (2007). Climate Change Induced Migration and Violent Conflict. Political Geography, 26, 656. http://dx.doi.org/10.1016/j.polgeo.2007.05.001

Scheffran, J. (2008). Climate Change and Security. Bulletin of the Atomic Scientists, 64, 19. http://dx.doi.org/10.2968/064002007 